\title{
Thermochemical reduction of pelletized gypsum mixed with carbonaceous reductants
}

\author{
SR Motaung ${ }^{1,3 *}$, JN Zvimba ${ }^{2}$, JP Maree ${ }^{3}$ and AV Kolesnikov ${ }^{4}$ \\ 'DST/CSIR National Centre for Nanostructured Materials, Council for Scientific and Industrial Research, Pretoria 0001, South Africa \\ ${ }^{2}$ CSIR Natural Resources and the Environment, Council for Scientific and Industrial Research, Pretoria 0001, South Africa \\ ${ }^{3}$ Department of Environmental, Water and Earth Science, Tshwane University of Technology, Pretoria 0001, South Africa \\ ${ }^{4}$ Department of Chemical and Metallurgical Engineering, Tshwane University of Technology, Pretoria 0001, South Africa
}

\begin{abstract}
The recovery of better quality waste gypsum during acid mine drainage (AMD) neutralization is one step closer to achieving downstream waste gypsum beneficiation for recovery of valuable materials. This can facilitate recovery of treatment costs and prevention of environmental pollution from gypsum waste-dumps. Thermal reduction using rotary kilns to recover valuable materials from waste gypsum remains a critical and controversial process because of waste gypsum handling problems, environmental pollution due to dust and gaseous emissions and poor conversion yields. In order to mitigate these problems and improve waste gypsum conversion yields, pelletization of waste gypsum in the presence of binders (starch and cellulose) was investigated. A laboratory-scale disc pelletizer was used to produce pellets from a mixture of coal and commercial gypsum or waste gypsum, generated during AMD neutralization, with starch and micro-crystalline cellulose used as binders. The pellets were subjected to high-temperature thermal treatment in a tube furnace to generate calcium sulphide $(\mathrm{CaS})$, an important intermediate for waste gypsum beneficiation. The kinetics of thermal conversion of pelletized waste gypsum to $\mathrm{CaS}$ were found to be highly dependent on furnace temperature. Results also showed that pelletization affords improved handling of waste gypsum while use of binders as additives significantly improved the CaS yield, with starch giving the better yield compared to cellulose.
\end{abstract}

Keywords: waste gypsum, binders, pelletization, tube furnace

\section{INTRODUCTION}

$\mathrm{CaSO}_{4}$ formed during pre-treatment of acid mine drainage (AMD) with hydrated lime is a resource that can be converted to CaS, an important intermediate for synthesis of a number of calcium compounds including $\mathrm{CaCO}_{3}$, which is a feed stock for AMD neutralization. Other saleable products such as sulphur may also be produced downstream and the recovery of these feed materials promotes the cost effectiveness of AMD treatment. The recovery of sulphur from waste gypsum in particular is very critical from a South African context for two reasons. Firstly, South Africa imports more than R1 billion worth of sulphur from Canada and other oil-producing countries (Maree, 2013) and, secondly, AMD remediation is currently under the spotlight as various stakeholders come together to find a lasting solution. A report prepared by a team of experts (Coetzee et al., 2012) appointed by the South African Government-appointed Inter-Ministerial Committee on AMD has recommended construction of a $20 \mathrm{M} / / \mathrm{d}$ emergency neutralization plant for AMD treatment as one of the short-term interventions to deal with large quantities of uncontrolled AMD decanting from the Witwatersrand's Western Basin. This short-term intervention plan provides an opportunity for recovery of saleable materials from waste gypsum generated during AMD neutralization, thereby contributing towards providing economically sustainable AMD remediation. Therefore the treatment and recycling of this material is beneficial. Zvimba et al. $(2011,2012)$ reported some opportunities for the treatment and recycling of gypsum whereby $\mathrm{CaCO}_{3}$ is recovered.

\footnotetext{
* To whom all correspondence should be addressed.

- +27 12841 4058; e-mail: smotaung@csir.co.za

Received 28 October 2014; accepted in revised form 13 March 2015
}

Thermal decomposition is the process used for the conversion of waste gypsum (hydrated $\mathrm{CaSO}_{4}$ ) to $\mathrm{CaS}$, from which saleable products such as $\mathrm{CaCO}_{3}, \mathrm{MgCO}_{3}$ and $\mathrm{S}$ can be recovered. Several authors have studied the conversion of $\mathrm{CaSO}_{4}$ into CaS through the carbothermal reaction (Zheng et al., 2013, Zheng et al., 2011, Nengovhela et al., 2007, Van der Merwe et al., 1999). Strydom et al. (1997) confirmed the need to perform thermal reduction of $\mathrm{CaSO}_{4}$ using carbon as a reducing agent in the absence of air, as air was observed to impact negatively on the conversion of $\mathrm{CaSO}_{4}$ to $\mathrm{CaS}$. While challenges to $\mathrm{CaSO}_{4}$ thermal reduction such as those reported by Strydom et al. (1997) are well known, further challenges generally not encountered at laboratory scale are likely upon scaling up of the process to full-scale application. One of these challenges to be overcome is the form in which the feed-stocks are introduced into the rotary kiln. In this regard, it may be necessary to introduce the feed-stocks in a compacted form to facilitate handling of waste gypsum and also to avoid the formation of dust in the kiln.

Pelletization is one of the techniques used to compact powdered material to make it handleable. Nengovhela et al. (2007) investigated and concluded that pelletization of gypsum-coal mixtures resulted in a higher $\mathrm{CaS}$ yield as compared to nonpelletized mixtures. However, the pellets need to be of acceptable mechanical strength to minimize disintegration during handling, transportation, storage and, eventually, thermal reduction. Binders such as starch and cellulose are known to improve the mechanical properties of agglomerates such as pellets. Moreover, starch and cellulose also act as reducing agents because of their carbon content, further increasing the reducing components in the pellets. Avicel PH 101, a brand of microcrystalline cellulose, though expensive, was used in this study, since Azubuike and Okhamafe (2012) reported that the physicochemical and thermal properties of low-cost microcrystalline 
powders derived from agricultural residues such as maize cobs are comparable to those of the commercial products such as Avicel PH 101. Starch is composed of carbon, hydrogen and oxygen in the ratio 6:10:5, respectively. Alex et al. (1997) pelletized gypsum, coal and laterite mixtures and compared the effects of starch, bentonite and sodium silicate as binders. The authors found that starch and bentonite improved the strength of the pellets. The current study investigated waste gypsum pelletization and the effects of using binders as well as binder content during thermal reduction in a tube furnace. The kinetic data were measured and a macrokinetic model of the $\mathrm{CaSO}_{4}$ thermal reduction by a mixture of carbon-containing components, formed as pellets, was proposed. The model allowed for the prediction of conversion rates for various process temperatures and could provide insight into the process when used together with a heat transfer model.

\section{MATERIALS AND METHODS}

\section{Feedstock}

Waste gypsum (95.54 \%) precipitated during AMD neutralization and commercial $\mathrm{CaSO}_{4}$ (Merck; 98.5\%) were used as feed-stocks in this study. Bituminous coal (60\% carbon content) of particle size $<750 \mu \mathrm{m}$ from Mpumalanga Province (South Africa) was used as reducing agent by preparing a sample mixture of 2.5:1 C: $\mathrm{CaSO}_{4} \cdot 2 \mathrm{H}_{2} \mathrm{O}$ molar ratio in the case of commercial $\mathrm{CaSO}_{4}$ and 1.9:1 C: $\mathrm{CaSO}_{4} \cdot 2 \mathrm{H}_{2} \mathrm{O}$ in the case of the precipitated gypsum. Food-grade starch (Protea Chemicals) and commercial microcrystalline cellulose (Fluka) were used as binders.

\section{Equipment}

A disc pelletizer (Fig. 1) operated at $20 \mathrm{r} / \mathrm{min}$ was used to prepare the pellets. An Elite tube furnace with a quartz protective

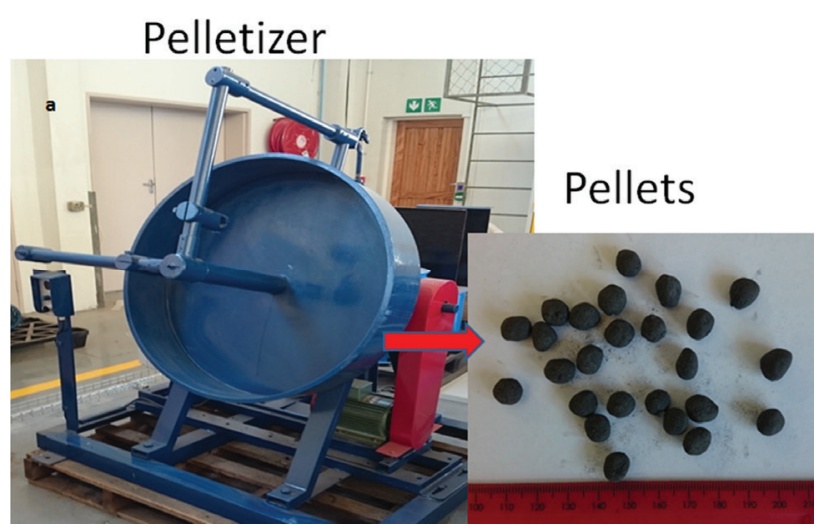

Figure 1

Pelletization of waste gypsum in a disc pelletizer

\begin{tabular}{|l|c|}
\hline \multicolumn{2}{|c|}{ Proximate analysis of coal sample } \\
\hline Parameter & Coal \\
\hline Inherent moisture (\%) & 2.9 \\
\hline Ash (\%) & 12.3 \\
\hline Volatile matter (\%) & 23.7 \\
\hline Fixed carbon (\%) & 61.1 \\
\hline
\end{tabular}

tube was used for the thermal reduction tests. Reagents were introduced in quartz boats into the tube furnace.

\section{Experimental procedure}

A sample made up of coal and commercial $\mathrm{CaSO}_{4}$ in the molar ratio 2.5:1 was divided into 6 portions. The 6 portions were mixed with $0 \%, 1 \%, 2 \%, 4 \%$, and $8 \%$, by mass, corn starch or microcrystalline cellulose (MCC), respectively. These mixtures were pelletized using a disk pelletizer with tap water simultaneously sprayed onto the sample to aid pellet formation. The average moisture content of the pellets was $25 \%$. The moisture content was determined by drying the pellets to a constant mass in an oven with a temperature pre-set at $105^{\circ} \mathrm{C}$ in an oven. The pellets were weighed into quartz boats before subjecting them to high-temperature thermal reduction in the tube furnace. Samples were heated for 5, 10, 15, and $20 \mathrm{~min}$. All of the samples were tested at $900^{\circ} \mathrm{C}, 1000^{\circ} \mathrm{C}, 1050^{\circ} \mathrm{C}$ and $1100^{\circ} \mathrm{C}$. Waste gypsum, precipitated during AMD neutralization, was also mixed with coal and $2.9 \%$ (by mass; based on the results in Fig. 2) starch and heated in the tube furnace at $900^{\circ} \mathrm{C}, 1000^{\circ} \mathrm{C}$, $1050^{\circ} \mathrm{C}$ and $1100^{\circ} \mathrm{C}$. The time intervals were $5,10,15$, and 20 min for each temperature range.

\section{Analytical procedure}

Coal proximate analyses was performed by the South African Bureau of Standards using the SANS 5925:2007, ISO 11712010, ISO 5622010 for the inherent moisture, ash and volatile matter, respectively. X-ray diffraction (XRD) analysis was performed using a PANalytical $x$-ray diffractometer equipped with a PIXel detector and fixed slits with iron-filtered cobalt Ka radiation. Phase identification was achieved using X'Pert Highscore Plus software. The relative phase amounts were estimated using the Rietveld method in percentage form. Sulphide was determined by standard iodometry (APHA, 1992), in which excess iodine which is mixed with the sample solution is titrated using sodium thiosulphate in the presence of starch indicator.

\section{RESULTS AND DISCUSSION}

\section{Feedstock characterization}

Waste gypsum was characterized by XRD and was found to be composed of $95.5 \%$ gypsum, $1 \%$ calcite and $3.5 \%$ hydrated $\mathrm{MgSO}_{4}$ (Epsomite). The proximate analyses of the reducing agent used in this study are presented in Table 1. As much as the carbon content is the main driving force of the carbothermal reduction process, the volatile matter is also expected to influence this reaction since most of the volatiles are composed of hydrocarbons and some sulphur. Solid-solid reactions are known to be slower; as a result the contribution by gaseous reactions from the constituents of the volatile matter will improve the rate of the reaction. Several authors have reported the main reducing agent during the thermal reduction process to be the gaseous intermediate (Gorkan et al., 2000; Oh and Whelock, 1990).

\section{Starch and cellulose as thermal reduction additives}

Figure 2 shows the effects of starch and cellulose (MCC) as thermal reduction additives while Fig. 3 shows the waste gypsum sludge thermo-reduction conversion curves. The CaS percentage yield in Fig. 2 was calculated using the Rietveld software. Corn starch is seen in Fig. 2 to be more effective in comparison to 
MCC in promoting thermal reduction when used as an additive during pelletization of waste gypsum. The carbon content of both starch and MCC appear to be beneficial in terms of increasing the conversion of waste gypsum to $\mathrm{CaS}$ during thermal decomposition. Therefore one can conclude that, in addition to improving the pellet's compactness, the two binders, starch and MCC, may also have catalytic effects on the decomposition reaction. In this regard, the addition of starch and MCC as binders is observed to have a positive effect on the conversion of waste gypsum to CaS, as given in Fig. 2 . Several factors are known to have either a positive or negative effect on the conversion of gypsum to $\mathrm{CaS}$. The presence of $\mathrm{O}_{2}$ and $\mathrm{CO}_{2}$ are undesirable since both favour the formation of $\mathrm{CaO}$ and $\mathrm{CaSO}_{4}$. Oh and Wheelock (1990) have reported that the presence of $\mathrm{SO}_{2}$ and $\mathrm{CO}_{2}$ at higher levels relative to $\mathrm{CO}$ favoured the formation of $\mathrm{CaO}$. Therefore, the desirable reaction condition for the effective thermal reduction of $\mathrm{CaSO}_{4}$ to $\mathrm{CaS}$ is excess amounts of CO in the kiln (Jagtap et al., 1990). Finney et al. (2009) have also reported that the addition of starch as a binder increased the percentage of $\mathrm{CO}$ in a reactor by more than $50 \%$ and decreased the oxygen content by up to $44 \%$ during the combustion of fuel pellets. This finding partly explains the improved yield of CaS during the thermal reduction of waste gypsum pellets using starch as an additive instead of MCC. Alternatively, the poor conversion of waste gypsum to CaS during thermal reduction using MCC as an additive relative to starch may also be attributed to the aromatic structure of MCC (Adel et al., 2011) that may not easily break to release carbon, hydrogen or oxygen during the thermal reaction.

The data given in Fig. 3 were generated from thermal reduction of pelletized waste gypsum precipitated during AMD neutralization with gypsum and starch in the ratio 1:2.9. The percentage yield of $\mathrm{CaS}$ during thermal reduction of waste gypsum from AMD neutralization, as given in Fig. 3, showed improved conversion as the reduction temperature was increased. Lower conversion of gypsum to CaS was observed at a temperature of $900^{\circ} \mathrm{C}$, even at the maximum reaction time (20 min). In contrast, a higher yield of $>80 \% \mathrm{CaS}$ was obtained at temperatures of $1000^{\circ} \mathrm{C}, 1050^{\circ} \mathrm{C}$ and $1100^{\circ} \mathrm{C}$ using thermal reduction times of $20 \mathrm{~min}, 15 \mathrm{~min}$ and $10 \mathrm{~min}$, respectively. Temperature plays an important role in the thermal decomposition studies of gypsum (Yan et al., 2014).

The XRD peaks presented in Fig. 4 showed that CaS was the predominant product under the experimental conditions used.

\section{Macrokinetic model of gypsum reduction by coal in the presence of starch and cellulose}

It was assumed that reduction of $\mathrm{CaSO}_{4}$ to $\mathrm{CaS}$ in the pellets, where the mixture of coal starch and cellulose serves as carbon source, takes place in the matrix of carbon-containing materials during gasification of these materials:

$$
\begin{aligned}
& \mathrm{CaSO}_{4}+4 \mathrm{C} \rightarrow \mathrm{CaS}+4 \mathrm{CO} \\
& \mathrm{CaSO}_{4}+4 \mathrm{CO} \rightarrow \mathrm{CaS}+4 \mathrm{CO}_{2} \\
& \mathrm{C}+\mathrm{CO}_{2} \rightarrow 2 \mathrm{CO}
\end{aligned}
$$

In this set of reactions the initial reduction of $\mathrm{CaSO}_{4}$ with carbon takes place according to Reaction 1 . The generated CO diffuses and reacts with $\mathrm{CaSO}_{4}$, which is not in contact with carbon, according to Reaction 2. Further, the $\mathrm{CO}_{2}$ evolved

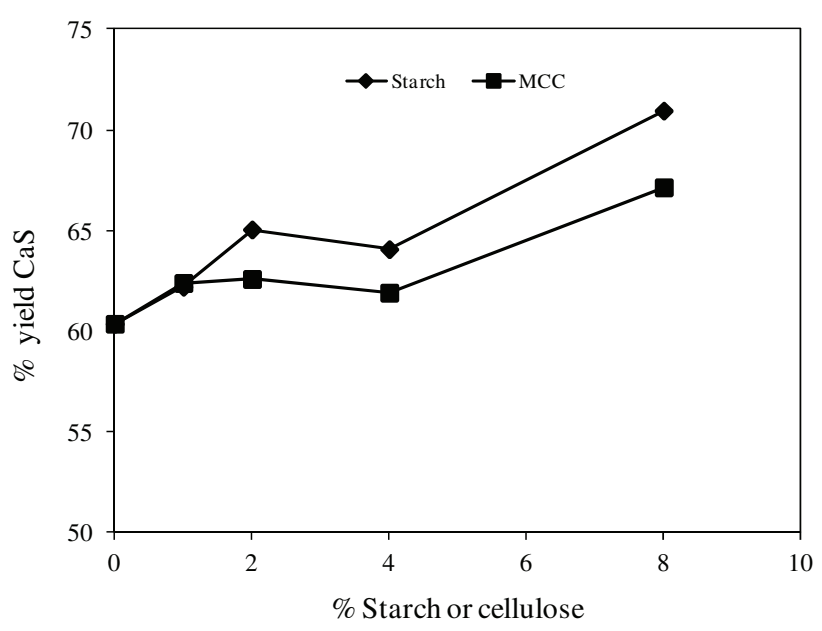

Figure 2

Effects of starch and cellulose (MCC) as thermal reduction additives

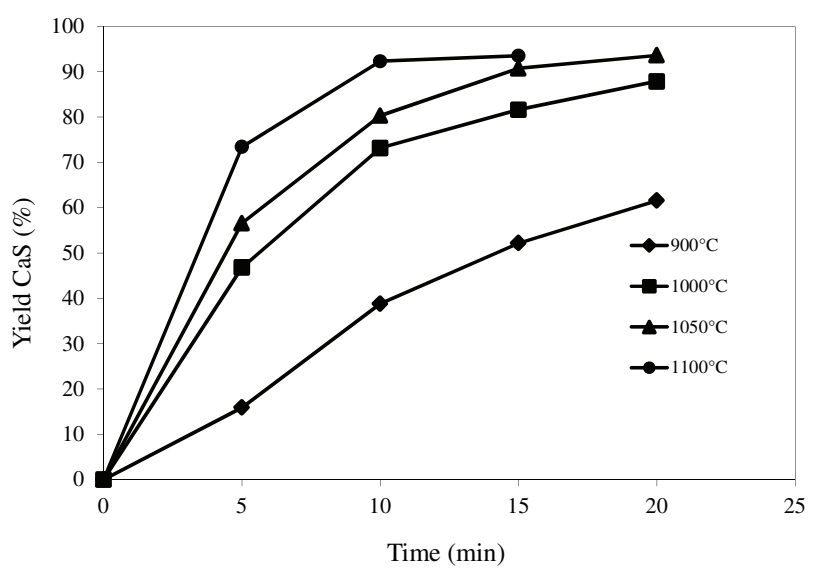

Figure 3

Conversion curves of thermo-reduction studies of waste gypsum sludge from AMD neutralization

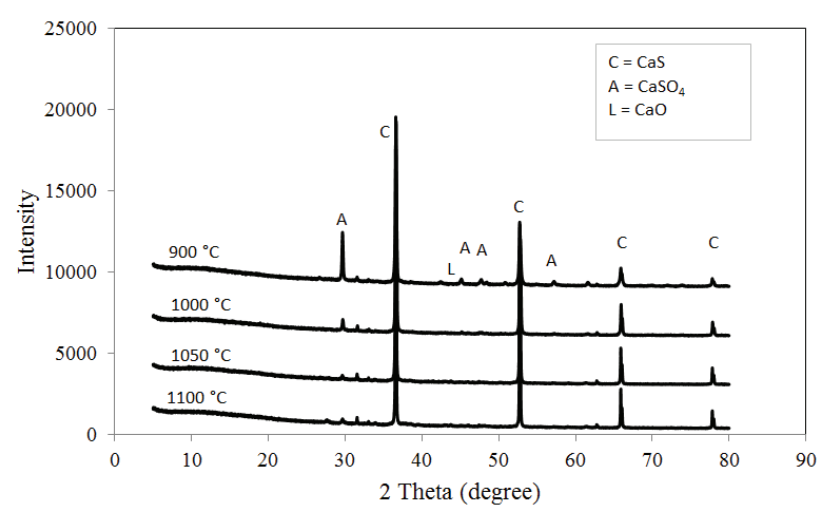

Figure 4

$X R D$ characterization of the products of the thermal decomposition experiments

diffuses back into carbonaceous materials to generate more $\mathrm{CO}$ according to the Boudouard reaction (Reaction 3 ). The proposed mechanism is similar to the mechanism of barite reduction by coal, discussed by Jagtap et al. (1990). Ma et al. (2011) reported that increasing the concentration of $\mathrm{CO}$ in the reactor favours the formation of $\mathrm{CaS}$ relative to $\mathrm{CaO}$. 
Kinetic parameters were obtained from the conversion curve presented in Fig. 3. The kinetic model equation proposed by Kasaoka and Sakata (1984) was used:

$$
x=1-\exp \left(-a \cdot \theta^{\mathrm{b}}\right)
$$

where: $x$ is the fractional conversion, $\theta$ is the time in seconds, and $a$ and $b$ are constant parameters.

This type of model is based on the shrinking core model and is capable of capturing the kinetic-controlled region, where reduction is controlled by gas phase reactions, which is the formation of gaseous intermediates such as CO. Parameter $a$ is related to the kinetic rate constant of the reaction and parameter $b$ to the physical changes occurring in the carbon matrix. The linearization of Eq. 4 gives:

$$
\ln (-\ln (1-\mathrm{x}))=\ln (a)+b \cdot \ln (\theta)
$$

The linearized equation is plotted in Fig. 5. The slope of the graph is equal to $b$ and intercept is equal to $a$.

The conversion data given in Fig. 5 by Eqs 4 and 5 allow solving for $\boldsymbol{a}$ and $\boldsymbol{b}$ for each temperature, T (see Table 2).

The rate of gasification of carbonaceous materials varies continuously with time due to continuous structural changes in the pellet. In such situations the reaction rate $k(x)$ will vary with time, and some average value should be used.

According to Kasaoka et al. (1983) the expression for the average rate constant, $k(x), \mathrm{s}^{-1}$ is given by:

$$
k(x)=a^{(1 / \mathrm{b})} b[-\ln (1-x)]^{(\mathrm{b}-1) / \mathrm{b}}
$$

As an indicator of the process rate, the typical conversion of $50 \%$ can be used to estimate the average reaction rate $k(x=0.5)$. The variation of the average reaction rate with temperature is given in Table 2.

Activation energy of the $\mathrm{CaSO}_{4}$ conversion, $E$, and preexponential factor, $A$, can be determined from the Arrhenius plot (Fig. 6).

The 'averaged' activation energy of $\mathrm{CaSO}_{4}$ reduction is equal to $90.0 \mathrm{~kJ} / \mathrm{mol}$, and pre-exponent $\mathrm{A}$ is equal to 7.39 . This lower activation energy may be attributed to the presence of starch, which was shown in Fig. 2 to be increasing the rate of the reaction. These values are different to the data reported by Kato et al. (2012) where another reaction mechanism (excluding gas phase reduction) was postulated and the activation energies of $370-400 \mathrm{~kJ} / \mathrm{mol}$ were reported for $\mathrm{CaSO}_{4}$ powder (sieve, $61 \mu \mathrm{m})$ reduction by solid coal particles $(31 \mu \mathrm{m})$ in a nitrogen atmosphere. As shown in Fig. 7, the macrokinetic model developed predicted conversion trends similar to the experimental kinetic data curves.
The model coefficients $a$ and $b$ vary with temperature. These highly nonlinear dependences can be represented by a neural network, similar to the case of $\mathrm{Fe}_{2} \mathrm{O}_{3}$ to $\mathrm{FeO}$ reduction process kinetics, reported by Piotrowski et al. (2005). Together with the energy balance model, the kinetic model can serve as a tool to investigate process trends and improve operation and design of furnaces and eventually pilot- and full-scale rotary kilns for $\mathrm{CaSO}_{4}$ reduction by carbon-containing materials.

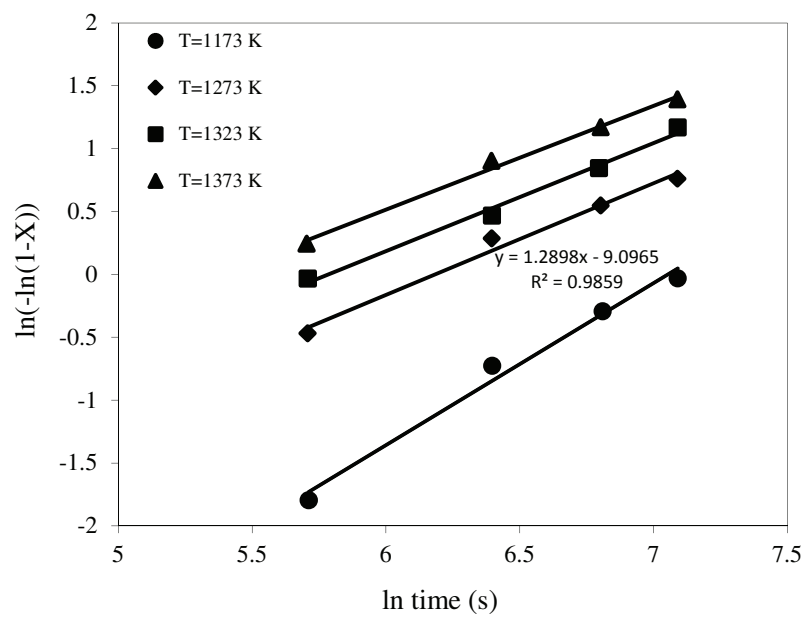

Figure 5

Conversion of $\mathrm{CaSO}_{4}$ represented by the linearized kinetic equation (Eq. 5)

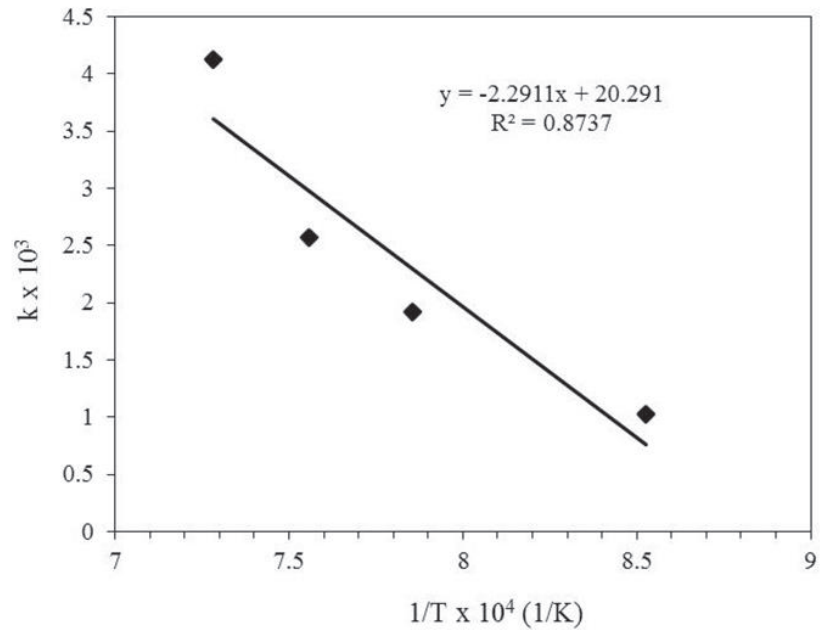

Figure 6

Arrhenius plot for the reduction of $\mathrm{CaSO}_{4}$ by carbonaceous materials

\begin{tabular}{|l|c|c|c|}
\hline \multicolumn{4}{|c|}{ Table 2 } \\
\hline Temperature, $\mathbf{K}$ & $\boldsymbol{a}$ & $\boldsymbol{b}$ & $\boldsymbol{k}^{\mathbf{s}}$ \\
\hline 1173 & $1.12 \times 10^{-4}$ & 1.29 & $1.02 \times 10^{-3}$ \\
\hline 1273 & $4.15 \times 10^{-3}$ & 0.89 & $1.92 \times 10^{-3}$ \\
\hline 1350 & $4.59 \times 10^{-3}$ & 0.91 & $2.57 \times 10^{-3}$ \\
\hline 1373 & $1.18 \times 10^{-2}$ & 0.83 & $4.13 \times 10^{-3}$ \\
\hline
\end{tabular}




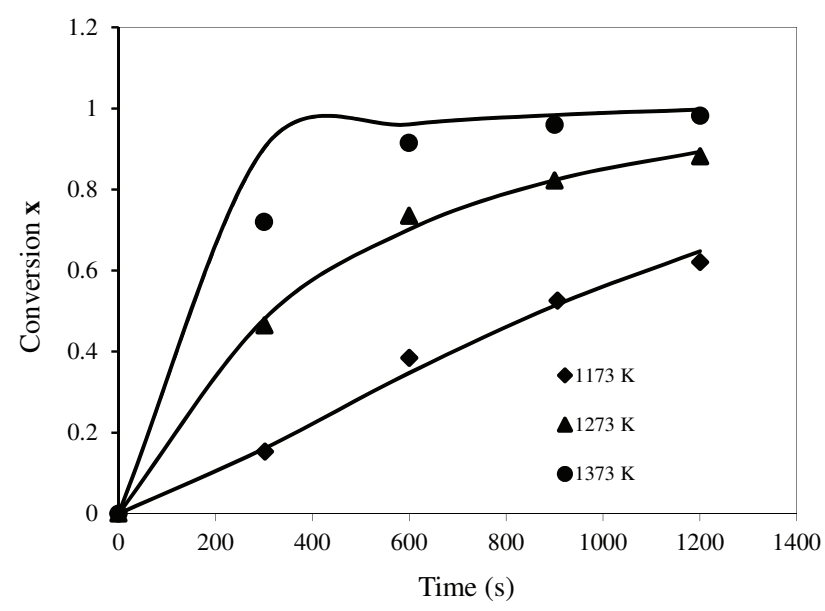

Figure 7

Conversion of $\mathrm{CaSO}_{4}$ at various temperatures Dots = experimental data (Fig. 3); solid lines = prediction by Eq. 5

\section{CONCLUSIONS}

This study has investigated pelletization of waste gypsum mixed with carbonaceous reductants as a means of improving handling of gypsum during thermal reduction to recover CaS, as well as promoting better conversion of the feed material. The effects of using binders, starch and microcrystalline cellulose were also investigated. In this regard, starch and MCC were observed to exhibit synergistic effects on the thermal reduction of the gypsum-coal pellets. The hetero-hydrocarbon structure of both starch and MCC appeared to be responsible for the promotion of the desired environment during the thermal reduction, as their decomposition results in the presence of extra $\mathrm{C}$, resulting in increased amounts of $\mathrm{CO}$ and decreased $\mathrm{O}_{2}$ levels. Starch was more effective compared to MCC in terms of improving the conversion rate of waste gypsum to CaS. The study also confirmed that pelletization of waste gypsum is possible and therefore facilitates waste gypsum handling. A maximum of $2.9 \%$ starch, by mass, was identified as suitable for waste gypsum pelletization.

As expected, temperature was confirmed to be the driving force for the thermal reduction. In this regard, low conversions were observed at $900^{\circ} \mathrm{C}$, with acceptable conversions realised when the temperature was increased to between $1000^{\circ} \mathrm{C}$ and $1100^{\circ} \mathrm{C}$.

\section{ACKNOWLEDGEMENTS}

This research was supported by the CSIR Thematic Fund and by Tshwane University of Technology. The authors also acknowledge Prof F Carlsson for editing this paper and Dr Sabine Verryn for XRD analysis.

\section{REFERENCES}

ADEL AM, ABD EL- WAHAB ZH, IBRAHIM AA and AL-SHEMY MT (2011) Characterization of microcrystalline cellulose prepared from lignocellulosic material Part II: Physicochemical properties. Carbohyd. Polym. 83 (2) 676-687.

ALEX TC, SRIVASTAVA JP, SRIKANTH S and PREMCHAND (1997) Pelletization of reactant dosed laterite. processing of fines. In: Proceedings of the National Seminar, 9-10 January 1997, NML Jamshedpur, India.
APHA, AWWA, WEF (1992) Standard Methods for the Examination of Water and Wastewater ( $19^{\text {th }}$ edn) American Public Health Association, Washington D.C.

AZUBUIKE CP and OKHAMAFE AO (2012) Physicochemical, spectroscopic and thermal properties of microcrystalline cellulose derived from cobs. Int. J. Recycl. Org. Waste Agric. 1 (9) 1-7.

COETZEE H, HOBBS PJ, BURGESS JE, THOMAS A, KEET M, YIBAS B, VAN TONDER D, NETILI F, RUST U, WADE P and MAREE JP (2010) Mine water management in the Witwatersrand gold fields with special emphasis on acid mine drainage. Report to the Inter-Ministerial Committee on Acid Mine Drainage. Department of Water Affairs, Pretoria. $128 \mathrm{pp}$.

FINNEY KN, SHARIFI VN and SWITHENBANK J (2009) Fuel pelletization with a binder: Part II-the impacts of binders on the combustion of spent mushroom compost-coal tailing pellets. Energy \& Fuel 23 3203-3210.

GORKAN AN, PRADA SD, PATHAK G and KULKARNI SS (2000) Vanadium catalysed gasification of carbon and its application in the carbothermic reduction of barite. Fuel 79 821-827.

JAGTAP SB, PANDE AR and GOKARN AN (1990) Effect of catalysts on the kinetics of the reduction of barite by carbon. Ind. Eng. Chem. Res. 29 795-799.

KASAOKA S, SAKATA Y, KAYANO S and MASUOKA Y (1983) Development of rate expressions and evaluation of reactivity for gasification of various coal chars with steam and oxygen. Int. Chem. Eng. 23 477-485.

KASAOKA S and SAKATA Y (1984) Fundamental study on development of catalytic coal gasification process. Reports of special project research on energy under grant-in-aid of scientific research. Ministry of Education, Science and Culture, Japan. 239-248.

KATO T, MURAKANI K, SUGAWARA K and MASUOKA Y (2012) Carbon reduction of gypsum produced from flue gas desulfurization. Chem. Eng. Trans. 29 805-810.

MA L, NIU X, HOU J, ZHEN S and XU W (2011) Reaction mechanism and influence factors analysis for calcium sulphide generation in the process of phosphogypsum decomposition. Thermochim. Acta $526163-168$.

MA L, NING P, ZHENG S, NIU X, ZHANG W and DU Y (2010) Reaction mechanism and kinetic analysis of the decomposition of phosphogypsum via a solid-state reaction. Ind. Eng. Chem. Res. 49 (8) 3597- 3602.

NENGOVHELA NR, STRYDOM CA, MAREE JP, OOSTHUIZEN S and THERON DJ (2007) Recovery of sulphur and calcium carbonate from waste gypsum. Water SA 33 (5) 741-747.

STRYDOM CA, GROENEWALD EM and POTGIETER JH (1997) Thermogravimetric studies on the synthesis of $\mathrm{CaS}$ from gypsum, $\mathrm{CaSO}_{4} \cdot 2 \mathrm{H}_{2} \mathrm{O}$, gypsum and phosphogypsum. J. Therm. Anal. 49 1501-1507.

OH JS and WHEELOCK TD (1990) Reductive decomposition of calcium sulphate with carbon monoxide: reaction mechanism. Ind. Eng. Chem. Res. 29 544-550.

PIOTROWSKI K, WILTOWSKI T, MONDAL K, STONAWSKI L, SZYMASKI T and DASGUPTA D (2005) Simultaneous influence of gas mixture composition and process temperature on $\mathrm{Fe}_{2} \mathrm{O}_{3}-\mathrm{FeO}$ reduction kinetics - Neural network modelling. Braz. J. Chem. Eng. 22 (3) 419-432.

VAN DER MERWE EM, STRYDOM CA and POTGIETER JH (1999) Thermogravimetric analysis of the reaction between carbon and $\mathrm{CaSO}_{4} \cdot 2 \mathrm{H}_{2} \mathrm{O}$, gypsum and phosphorgypsum in an inert atmosphere. Thermochim. Acta 340 \& 341 431-437.

YAN B, MA L, MA J, ZI M and YAN X (2014) Mechanism analysis of $\mathrm{Ca}, \mathrm{S}$ transformation in phosphogypsum decomposition with $\mathrm{Fe}$ catalyst. Ind. Eng. Chem. Res. 53 7648-7654.

ZHENG D, LU H, SUN X, LIU X, HAN W and WANG L (2013) Reaction mechanism of reductive decomposition of FGD gypsum with anthracite. Thermochim. Acta 559 23-31.

ZHENG S, NING P, MA L, NIU X, ZHANG W and CHEN Y (2011) Reductive decomposition of phosphogypsum with high-sulfur concentration coal to $\mathrm{SO}_{2}$ in an inert atmosphere. Chem. Eng. Res. Des 89 2376-2741. 
ZVIMBA JN, MULOPO J, BOLOGO LT and MASHEGO M (2011)

The dissolution characteristics of calcium sulfide and utilization as a precipitation agent in acidic wastewater effluent treatment. Water Sci. Technol. 63 (12) 2860-2866.
ZVIMBA JN, MULOPO J, BOLOGO LT and MATHYE M (2012) An evaluation of waste gypsum-based precipitated calcium carbonate for acid mine drainage neutralization. Water Sci. Technol. 16 (9) 1577-1582. 